\title{
Personality Disorder and Verbal Behavior
}

Charlotte Entwistle ${ }^{1}$, Ely Marceau ${ }^{2}$, and Ryan L. Boyd $d^{1,3,4}$

${ }^{1}$ Department of Psychology, Lancaster University, United Kingdom

${ }^{2}$ School of Psychology and Illawarra Health and Medical Research Institute, University of Wollongong, Australia

${ }^{3}$ Security Lancaster, Lancaster University, United Kingdom

${ }^{4}$ Data Science Institute, Lancaster University, United Kingdom

\section{Author Notes / Acknowledgements}

Preparation of this manuscript was funded, in part, by a grant from the Swiss National Science Foundation (\#196255). Ms. Entwistle's contributions were made as part of her PhD at Lancaster University, funded by the Engineering and Physical Sciences Research Council. The authors would also like to thank Morteza Dehghani for his insightful feedback and comments on an earlier draft of this manuscript. 


\section{Personality Disorder and Verbal Behavior}

The central goal of psychological science, broadly defined, is to discover and understand universal rules that govern our mental worlds - namely, our thoughts, feelings, and behaviors. Social psychology, for example, explores how different social forces influence a person's emotional, cognitive, and behavioral processes. Educational psychology is typically concerned with how people absorb, process, recall, and deploy new ideas and information. The study of personality and individual differences, on the other hand, is geared towards identifying, describing, and explaining the ways in which people differ from one another. Why are some people highly motivated to learn new skills whereas others are not? What causes some people to get anxious more easily than others? Why do some people run into a burning building to save a life while everyone else runs away?

In most cases, the study of personality centres around normative differences that typify important, but relatively "neutral”, variations between individuals. Whether a person prefers reading books or going to parties, what we generally care about is understanding the potential ways in which people differ, and how all of these possible "ways of differing” contribute to each person's unique psychological composition. When we talk about personality dimensions like extraversion, for example, we implicitly acknowledge that most people fall somewhere in the "meaty” part of the bell curve; very few people are extremely extraverted or extremely introverted. Despite the fact that we often talk about personality as 
“either/or” types, psychologists quietly acknowledge that studying the relatively small number of extreme cases in either direction (e.g., those statistically rare cases of extraordinarily extraverted or introverted people) does not usually tell us much about how most people function, psychologically.

Some areas of personality research, however, are focused precisely on these more extreme variations between people; the people at the tail ends of the bell curve. When an individual's personality deviates from social norms to the point of causing personal and interpersonal complications, we move into the territory of talking about pathological personalities, or personality disorders. Personality disorders are typically defined as pervasive patterns of maladaptive traits and behaviors, beginning in early adult life, which lead to substantial personal distress or social dysfunction, or both, and disruption to others (American Psychiatric Association, 2013). An adult who bursts into tears at the slightest inconvenience, a person who desperately and excessively latches on to others, and a person who sabotages all of their friendships due to envy all exhibit non-normative or extreme behaviors. Importantly, these behaviors are likely to have seriously negative consequences in their day-to-day lives: the emotionally fragile individual may unintentionally drive others away, the socially desperate individual may end up with feelings of abandonment and loneliness when rejected, and the saboteur may be subjected to serious social blowback. Today, the development of new technologies means that there are many advanced tools that can be used to improve our understanding of personality disorder, and, in turn, the treatment of personality disorder. One particularly promising tool — indeed, the focus of this chapter — is computerized language analysis. Through the exploration and analysis of verbal behavior, it is possible to empirically develop new insights into personality disorder, broadly defined. That is, by looking at patterns in the way that people with personality disorder use language — the words that they use and the way in which they use them — we can gain 
access into their broad constellation of thinking, feelings, and behaviors, as well as how precisely each of these features contributes to their pathology.

To date, however, there has been very little research at the intersection of verbal behavior and personality pathology. Accordingly, the goal of this chapter is to describe and discuss how personality disorder may become better understood through the application of natural language analysis, providing a rough roadmap for the development of personality disorder studies using modern methods. Specifically, in this chapter we will provide:

1. A brief background and overview of personality disorder;

2. An overview of how natural language processing (NLP) methods have advanced understanding within the wider field of psychology, focusing on personality psychology and psychopathology specifically;

3. Examples that demonstrate how NLP methods can help to resolve some of the fundamental, unanswered questions and debates in the personality disorder literature.

\section{A (Very) Brief Overview of Personality Pathology}

The idea of personality pathology has a long history, tracing back at least as far as 192 AD. The ancient Roman physician and philosopher Galen conceptualised four "temperaments," or personality types, on the basis of four bodily fluids known as the Hippocratic humours. The four primary humours — blood, yellow bile, black bile, and phlegm - were understood according to general cosmological theory, whereby they were thought to be manifestations of four primary elements: air, fire, earth, and water. For example, black bile (i.e., "melanchole") was thought to be a manifestation of earth, characterised by coldness and dryness. An excess of “cold and dry” qualities were thought to characterise depression, both metaphorically and literally, suggesting some form of 
association between the melanchole humour itself and depression (Stelmack \& Stalikas, 1991).

In recent decades, personality disorders have received considerable scientific, clinical, and societal attention (Tyrer et al., 2015), and are now among some of the most commonly diagnosed psychological disorders. In a recent systematic review and meta-analysis examining the global prevalence of personality disorder, a worldwide prevalence of $7.8 \%$ was reported for personality disorder in the general population (Winsper et al., 2020). To put this into context, the worldwide prevalence of anxiety disorders has been estimated to be $6.7 \%$ (Steel et al., 2014) and schizophrenia less than 1\% (Charlson et al., 2018). Prevalence rates of personality disorders are even higher in clinical populations: around a quarter of all patients in primary care, half of all patients in psychiatric outpatient settings, and two-thirds of prisoners meet the diagnostic criteria for at least one personality disorder (Tyrer et al., 2015), illustrating the high social and economic costs associated with personality disorder.

Valuably, greater empirical attention has led to improvements in our knowledge of personality disorders. For instance, psychologists have begun to find that various types of personality disorder all share some fundamental commonalities — for example, it is now widely agreed that interpersonal and affective dysfunction are right at the core of personality disorder (Wright \& Simms, 2016). Specifically, people with personality disorder tend to experience some combination of social difficulties (e.g., social withdrawal; fear of abandonment), issues around their identity (e.g., being unsure of who they are as a person), and emotional problems (e.g., extreme emotional fluctuations; shallow emotions).

Relatedly, like most forms of psychopathology, personality disorders are almost universally typified by problematic behavior. We all regularly engage in behaviors to cope with or regulate our thoughts and feelings, such as exercising or listening to music. However, we sometimes adopt problematic self-regulatory behaviors that are harmful to ourselves 
and/or others — we may pick a fight with our spouse or overeat when feeling overwhelmed by stress from our job, for example. Such behaviors are known as maladaptive regulatory behaviors and are seen at elevated rates (and in more extreme forms) in people with personality disorder. For instance, self-injurious behavior (such as intentionally cutting oneself) is an example of a maladaptive regulatory behavior particularly common among people with personality disorder, in which this behavior is often undertaken in an attempt to deal with or relieve feelings of intense negative emotion (e.g., Buckholdt et al., 2015). One explanation as to why people with personality disorder engage in maladaptive regulatory behaviors at an elevated rate is that these behaviors could be an attempt to manage the emotional dysregulation that they experience (Carpenter \& Trull, 2013). Further, it is likely that people suffering from personality pathology have exhausted other options for relief from their emotions.

Personality disorder is also associated with greatly elevated threats to well-being, such as increased rates of aggression, physical ailments, and death by suicide (Frankenburg \& Zanarini, 2004; Gilbert et al., 2013; Schneider et al., 2008). Concerns over the well-being and life outcomes of people with personality disorder are further amplified by the fact that personality disorders have historically been notoriously difficult to treat — medications are generally ineffective for managing social and identity problems, and individuals with personality disorder are sometimes resistant to therapy (Gabbard, 2012), with more than one third of people with personality disorder dropping out of treatment prematurely (McMurran et al., 2010). Thus, individuals with personality disorder are at a particularly high risk for negative outcomes.

Despite advances in characterizing the etiology of personality disorder development and manifestation over time (e.g., Winsper, 2018), there remains much to be uncovered regarding the underlying structure and manifestation of the disorder and the provision of 
effective treatment. Given the high risk and high prevalence, more empirical research driven towards developing a greater understanding of personality disorder is essential. Such advances in knowledge would crucially inform clinical practice and, in turn, would benefit those with lived experience of personality disorder, their family and carers, and wider society (Barr et al., 2020). Valuably, natural language analysis is one technique that has the potential to improve our understanding of personality disorder.

\section{Psychology and Language}

Verbal behavior analysis has a long history in psychology, particularly in understanding personality and psychopathology. Given that personality disorder rests at the intersection of personality and psychopathology, it is instructive to consider how NLP is often applied to each respective area individually. If NLP methods can help to improve our understanding of both personality and psychopathology individually, we are optimistic that these methods will be critical tools in helping us to better understand personality disorder as well.

\section{Language Analysis and Personality}

Personality psychology has strong roots in the study of language. Indeed, much of our current knowledge surrounding personality dimensions descends directly from the "lexical approach” to individual differences. Briefly described, the lexical approach to understanding personality and personality structure is based on the assumption that meaningful individual differences will naturally become encoded in the ways in which we describe ourselves and others - our words. Put another way, the lexical approach to personality generally assumes that humans naturally evaluate what makes each person different from one another, and that we logically use words to express, understand, and convey those interpersonal differences 
that are psychosocially important. The lexical hypothesis has been elaborated on by several personality researchers, including the reduction of trait descriptors down to the most "central" dimensions of personality (Allport, 1937; Cattell, 1943; John et al., 1988).

Whereas the lexical hypothesis is often used to describe how patterns in language can inform our understanding of personality in the broadest terms, a sizeable body of research has demonstrated that individual patterns of language use can also be psychologically revealing. Rather than mapping out the structure of personality from Webster's dictionary, the idiosyncratic ways in which a given person speaks, writes, and types have been shown to reveal what a person pays attention to in the world around them or, put simply, their “attentional habits” (see Boyd \& Schwartz, 2021). For example, we expect that — by definition — extraverts will attend more to their social environments than introverts; indeed, there is considerable evidence to date that extraverts use relatively high rates of social words (e.g., "friend," "family,” and "people”) when compared to introverts (Mairesse et al., 2007). Similarly, people with insecure attachment styles have been found to attend more to themselves as individuals and attend less to themselves in connection with others, as evidenced by higher rates of $1^{\text {st }}$ person singular pronouns, or " $I$-words", and lower rates of $1^{\text {st }}$ person plural pronouns, or “we-words” (Dunlop et al., 2020).

Imagine two people who go out to dinner with a group of mutual acquaintances. Both individuals go through similar behaviors: they each take a shower, get dressed, drive to the restaurant, order a meal, eat, socialize, and return home. However, when asked "What did you do last night?”, each person answers the question differently. The first person, Nathan, says "I went to a restaurant and got myself some dinner.” The second person, Colin, says “All of us met up at a restaurant and enjoyed a lovely meal with friends.” There is a world of difference, psychologically speaking, between Nathan and Colin; the two sentences not only have different meaning in the literal, linguistic sense, but they also provide a logical route to 
each person's subjective thoughts and experience of the event. For instance, Nathan's statement is self-focused and relatively neutral, telling us that he is likely to be far less socially connected than Colin. These differences are both subtle and striking at the same time. Colin's use of we-words (“us”) and social words (“friends”) can be easily detected by a computer program, despite the fact that the program will have no idea what either sentence actually means. In turn, this means that even the simplest computer programs can be used to take a person's language and convert it into measures of their attentional patterns and, consequently, their psychological traits.

Importantly, the use of language analysis has provided unique insights into personality theories that would otherwise have been difficult to capture through traditional assessment methods. To illustrate how NLP methods have helped to improve understanding of personality, two examples of important lessons we have learned using language analysis include: 1) core dimensions of personality can be traced in language, and 2) how the core personality components fit together to "form" one’s personality and how these components operate in the real-world.

\section{Lesson 1: Dimensions of Personality can be Traced in Language}

The use of natural language analysis has revealed new and interesting dimensions of personality that have not been possible to uncover from traditional methods. For example, insightful early research was conducted by Pennebaker and King (1999), which involved conducting factor analysis on linguistic features derived from natural language data; namely, from student essays. From the language factors generated, core dimensions of personality, or “thinking-styles", were revealed to be reflected in language. Valuably, this uncovered the possibility of construing personality at an individual level in terms of the language a person uses, demonstrating how language can be used to gain insight into the underlying structure of personality. 
Building on this further, a recent study used language from social media posts to develop a new structural model of personality (Kulkarni et al., 2018). In this study, factor analysis was used to derive a trait model based on everyday language; analysing people’s words to infer their psychological traits. From this, it was made clear that, perhaps unsurprisingly, different people tend to talk in different ways. These various "dimensions of language” can be thought of as different “dimensions of thinking”, which predicted important outcomes, such as intelligence and socioeconomic status. Interestingly, the trait model generated from language differed considerably from the traditional Big 5 personality model. The language-derived trait model therefore allowed for previously unknown insights into the underlying structure of personality, in that it helped to uncover personality dimensions from a new angle. Moreover, this trait model was able to compete with the Big 5 model in terms of generalisability and stability of factors, and was found to have test-retest reliability, predictive validity, and face validity. Thus, this indicates the potential of using NLP methods to learn about the core components and structure of personality in a way that supersedes traditional psychometric approaches, allowing for new contributions to existing personality theories.

\section{Lesson 2: Language Analysis Reveals How Personality Components Operate in the Real-}

\section{World}

To date, there has been an impressively large body of research working to map out the underlying structure of personality (Digman, 1990; Eysenck, 1991). However, much of the goal of personality research is to understand how personality operates in the real world and influences a person's actual behavior — that is, we are often interested in not just the "form” of personality, but the "function" of personality for the individual. The analysis of natural language can provide insight in this respect. For example, extraversion has been associated with greater words spoken and more social language, and this pattern of verbal behavior was 
also associated with nonverbal social behavior, such as spending more time on the phone and around other people (Tackman et al., in press). The use of language as a behavioral measure of a person's psychology demonstrates the possibility of gaining new insights into what personality looks like and how it impacts on a person's actual behavior from a new perspective, revealing interesting interactions between personality and real-life situations not seen before.

In addition, NLP methods have the potential to detect individual differences in the real-world with greater accuracy than traditional self-report methods. That is, research incorporating NLP methods can overcome some of the systematic biases associated with selfreports — particularly self-enhancement biases — to uncover meaningful individual differences in psychological well-being (Wojcik et al., 2015). In fact, the conclusion from studies with findings based on self-reports - that political conservatives have greater happiness and psychological well-being than political liberals (Onraet et al., 2013) — was directly contradicted by compelling findings derived from behavioral measures. Contrary to questionnaire-based findings, the analysis of verbal and nonverbal behavior revealed that liberals in fact experience and express greater happiness than conservatives, evidenced by behavioral indicators such as more intense and genuine smiles and higher rates of positive emotion language (Wojcik et al., 2015). Conservatives report being happier on a questionnaire, but their actual behavior does not support this, suggesting that the questionnaire findings were at least partially driven by self-enhancement motives, highlighting the limitations of relying on self-report measures alone to study individual differences.

\section{Language Analysis and Psychopathology}


Research on psychopathology is, in many ways, historically interwoven with the idea that our words reflect some of our deepest thoughts, feelings, and behaviors, often unconsciously. For instance, Freud viewed language as a pathway to studying the unconscious forces at work in our minds, and he focused a considerable amount of his life on understanding verbal behavior. In his early work, Freud (1891) proposed a theory of language, whereby he discussed its nature in relation to thought and consciousness and its origins as an instrument of social communication. He also specifically associated language with psychosis, suggesting that dysfunction in word-presentation association processes was the underlying cause of incoherent speech in people with psychosis (Freud, 1915).

In more recent years, psychodynamic thinking remained closely tied to the study of language as a way to understand and explain psychological disorders. Colin Martindale (1975a), for example, proposed that cognition occurs along a continuum, ranging from regressed (unconscious, primary-process) to conscious (secondary-process) thought. Martindale (1975a), like many others of his time, believed that psychopathology (including personality pathology) was a consequence of being in a state of regressed thought and language. From this perspective, people experiencing psychopathology were thought to be "stuck" at an unconscious level of thought, focused solely on primary drives (e.g., sexual drives) and lacking higher level cognitive processes, such as insight and self-awareness, and this cognitive state was believed to be directly visible in a person's language.

Relatedly, in the field of psychotherapy process-outcome research, early pioneering work considered language analysis as a potent methodological tool. For example, Mergenthaler and Kächele (1988) reported on establishing a “computerized databank” to store, organise, and analyze a large volume of verbatim transcripts of psychotherapy sessions. More recently, at the turn of the new millennium, the development of the computerized Gottschalk-Gleser content analysis method (Gottschalk, 2000) facilitated measurement of a 
magnitude of psychobiological states and traits, such as anxiety and hostility, from the content analysis of verbal behavior. Importantly, computerized methods for quantifying verbal behavior were able to overcome the high demands of manual application, such as significant training requirements and time-intensive hand scoring of transcripts. Such early research incorporating language analysis methods generated a burgeoning interest in the use of modern NLP methods to better manage the complexities of psychotherapeutic processes and better understand treatment outcomes (Pace et al., 2016).

With the rise of personal computing, social media, and smart technology, there has been a recent surge of empirical research incorporating NLP methods to study and understand psychopathology. Much like research on personality, language analysis can help us to understand psychopathology by providing implicit and unobtrusive insight into the core underlying psychology, motivations, and behaviors of people with psychological disorders, allowing for greater understanding of the true nature of such disorders.

Parallel to our examples above, we will briefly illustrate how NLP methods can help to grow our understanding of psychopathology, broadly defined. Namely, we again highlight lessons from NLP research that 1) have helped to pinpoint the nature and structure of psychological disorders, and 2) demonstrate the ability of natural language data to unobtrusively measure and track the progression of psychopathology over time.

\section{Lesson 1: Language Analysis Allows Insight into the Nature and Structure of}

\section{Psychological Disorders}

Perhaps the most consistent and exemplary finding in clinical NLP research to date is that people with depression tend to use language differently than those without depression, reflecting a generally different social and attentional orientation. Across dozens of studies, individuals with depression are consistently found to use $1^{\text {st }}$ person singular pronouns — that is, self-referential words such as $I, m e$, and my — at relatively high rates, indicating 
something of an excessive self-focus or an inability to "get out of their own heads" (e.g., Edwards \& Holtzman, 2017; Sonnenschein et al., 2018; Zimmermann et al., 2017).

Additional work has helped to extend the nomological network surrounding depression, allowing for better and more accurate typification of the disorder. For example, research exploring the language of individuals suffering from depression finds that they are more prone to“all-or-nothing” thinking, as evidenced by relatively high use of "absolutist” language, such as “always” and "never” (Al-Mosaiwi \& Johnstone, 2018), and use language indicative of greater cognitive load (e.g., “think”, “ought”; Eichstaedt et al., 2018). Thus, the analysis of language has allowed for valuable insights into the underlying nature of depression, in that it has revealed that self-focus is in fact a consistent, trait-like characteristic of depression, rather than simply a small feature of depression that is only sometimes present. Ideally, this knowledge will improve treatment through providing a target for clinical interventions.

In the domain of psychotic disorders, language analysis has also helped to improve our understanding of the nature of schizophrenia. Schizophrenia is primarily characterized by psychotic symptoms (e.g., hallucinations, delusions), including externalizing biases and paranoid thinking, as well as interpersonal dysfunction and disorganized speech and behavior (APA, 2013). Interestingly, these clinical characteristics can generally be found in language. In particular, people with schizophrenia will often use considerably more external references (i.e., $3^{\text {rd }}$ person plural pronouns, such as “they”) in their language compared to the general population (Coppersmith et al., 2015; Fineberg et al., 2015; Lyons et al., 2018). This aligns with the core clinical features of schizophrenia — specifically, the interpersonal dysfunction, externalising biases, and paranoid thinking components — suggesting that elevated use of $3^{\text {rd }}$ person pronouns might be a useful indicator of the disorder. 
Furthermore, NLP research has also uncovered markers of mental distress in people with schizophrenia, with associations found between schizophrenia and greater use of healthrelated words, negative emotion words, and $1^{\text {st }}$ person singular pronouns (Zomick et al., 2019). The finding of the relatively high use of health-related words among people with schizophrenia is particularly interesting as this provides new insights into the nature of the disorder, in that excessive focus on health may be a central component of schizophrenia, a notion that has not yet been theoretically established.

\section{Lesson 2: Language can Assist with Measuring and Tracking Psychopathology Over Time}

Accurate assessment and monitoring of psychological disorders is necessary for informing appropriate diagnosis and treatment. Inaccurate measurement of a disorder can have profoundly negative consequences and has the potential to result in life changing outcomes for the people affected. For example, misdiagnosis of bipolar disorder has resulted in delays in the provision of appropriate treatment, subsequently leading to increased risk and negative outcomes for those affected, such as increased suicide risk, length of hospitalization, and social impairment (Altamura et al., 2015). The ability to measure and track psychopathology also allows for the evaluation of clinical treatments, by monitoring individual responses to treatment in real-time, and so it plays a vital role in the development of effective, individualized treatments. Moreover, it is essential that psychological disorders can be accurately and unobtrusively monitored so that it is possible to observe how a given disorder manifests over time, which would provide insight into the developmental trajectory of a psychological disorder. Vitally, NLP methods have the potential to make important contributions to both the measurement and tracking of psychopathology over time.

To date, numerous studies have used linguistic markers to detect and track changes in psychopathology. For instance, through measuring linguistic markers of mental distress (e.g., $1^{\text {st }}$ person singular pronouns, negative emotion words) and observing changes in these 
patterns over time, studies have been able to measure and observe changes in general psychological well-being and mental distress at a large-scale (e.g., Bagroy et al., 2017; Guntuku et al., 2020). Specifically, in one study, a machine-learning model built on social media data could detect mental health expressions (i.e., words and phrases related to mental health) with 97\% accuracy, which resulted in the development of a "Mental Well-being Index” (Bagroy et al., 2017). Vitally, this index was able to predict the prevalence of mental health issues across different universities.

Importantly, the ability to detect the presence of psychopathology through language means that linguistic features could be used alongside other, more traditional measures in the assessment of psychological disorders, providing an unobtrusive and implicit contribution to the measurement of psychopathology. For example, reliable linguistic markers of mental distress (e.g., $1^{\text {st }}$ person singular pronouns) could be incorporated as additional outcome measures, alongside other clinical outcome measures (e.g., self-report mental health measures, clinician-rated measures), in the assessment of general mental distress in people undergoing a psychological therapy, to evaluate the effectiveness of such therapy.

Moreover, language has been used to monitor specific psychological disorders. This has consistently been demonstrated with depression (e.g., Dean \& Boyd, 2020; Schwartz et al., 2014; Park \& Conway, 2017), whereby changes in depressive states have been successfully measured through language. Relatedly, changes in suicidal ideation can also be precisely detected and measured through language (e.g., De Choudhury et al., 2016; MaKellams et al., 2016). Specifically, in one study, through measuring changes in language on social media, it was possible to predict with high accuracy whether a given person would make a post on an online suicide help forum, which is a strong indicator of suicidal ideation (De Choudhury et al., 2016). The ability to detect depression and suicidal ideation through language has obvious clinical implications: when detected, clinical interventions can be 
provided to try to address such depressive symptoms and suicidal thoughts before they worsen.

Similarly, language has been used to measure changes in psychotic symptoms. Through the examination of changes in language used in social media posts, research has been able to measure and predict changes in psychotic symptoms, such as the occurrence of delusions and hallucinations (Birnbaum et al., 2019). Most importantly, this research also revealed the possibility of identifying early warning signs of psychotic relapse through linguistic and behavioral markers. Specifically, increased use of negative emotion words, swear words, death words, and $1^{\text {st }}$ and $2^{\text {nd }}$ person pronouns were strong predictors of psychotic relapse. A machine learning model developed from linguistic and behavioral features identified in the study was able to predict psychotic relapse with $71 \%$ accuracy. Importantly, this ability to accurately detect and monitor psychopathology means that individualized clinical interventions can be provided in a timely manner.

\section{Personality Disorder and Language Analysis}

Today's automated language analysis methods have made it possible, and very accessible, to conduct large-scale, objective linguistic analyses to gain insight into people’s underlying psychological and personality processes. However, what is peculiar is that, despite the success of NLP methods in the fields of psychopathology and personality psychology individually, these areas of research have not been brought together in a general, formalized way. This lack of unification across disciplines is particularly strange given the relatedness and intertwining nature of psychopathology and personality psychology. Right at the core of the intersection of personality and psychopathology are personality disorders (see Figure 1). 
Compared to psychopathology and personality research, the use of computational language analysis in the study of personality disorder is much more rare. If we can conduct insightful personality and psychopathology research using NLP methods, we should be able to conduct insightful personality disorder research using the same approaches, given the high degree of interconnectedness across each area. Accordingly, the remainder of the chapter will integrate core ideas at the personality-language intersection with those at the psychopathology-language intersection, providing views and recommendations for how we can begin to fill the major gaps in knowledge in this area.

\section{Using Language Analysis to Understand Personality Disorder}

As in personality and psychopathology research, language analysis methods have the potential to help to improve our understanding of personality disorder, which, in turn, would have positive implications on the treatment of personality disorder. Specifically, we can use NLP methods to help to shed light on the answers to some of the major open questions and debates in the personality disorder literature. In particular, two large, frequently debated topics in the personality disorder literature surround the assessment of personality disorder and the developmental trajectory of personality disorder across the lifespan. Accordingly, we will discuss and provide examples describing how language analysis can insightfully contribute to these debates.

\section{How Should We Assess Personality Disorder?}

How personality disorders should be assessed is heavily debated (see Kim \& Tyrer, 2010), particularly in terms of the measurement, assessment, and classification procedures. This topic is especially important given that the assessment and classification of personality 
disorder directly impacts on treatment decisions: an individual can only be provided with appropriate treatment for an affliction when it has been accurately determined what affliction treatment needs to be provided for. If the assessment and diagnosis procedure fail to accurately identify a person as having a personality disorder, the opportunity to provide appropriate and essential treatment in a timely manner may be missed.

\section{How is Personality Disorder Currently Assessed?}

Personality disorder diagnosis typically involves multiple clinical assessments through structured interviews, in which a clinician asks about a person’s life, feelings, thoughts, and behaviors, along with self-report and observer-report (i.e., reports from other people who are not being assessed, such as family or friends) measures to assess the quantity and severity of personality disorder features. Clinical observations of how a person behaves and examinations of psychiatric history and medical records (e.g., previous hospitalizations) are also sometimes carried out as part of the assessment procedure. Such assessment methods are currently used to measure and classify distinct personality disorders (e.g., borderline personality disorder) based on clinical features specific to a given personality disorder.

To illustrate the personality disorder diagnostic procedure, imagine a woman named Lucy. Lucy has recently become an inpatient in a psychiatric hospital due to intense suicidal ideation. After having discussions with Lucy about her mental health and past experiences, and after examining her clinical history and observations from clinical staff, the psychiatrist responsible for Lucy’s care suspected that she might have a personality disorder. To investigate the possibility that Lucy does indeed have a personality disorder, the responsible clinician decides to carry out a clinical interview using a personality disorder assessment measure, which assesses Lucy’s personality disorder symptoms (e.g., impulsivity, self-harm) based on diagnostic criteria. From this assessment, and taking into account Lucy’s clinical notes and clinical history, the clinician concluded that Lucy does in fact meet the criteria for 
personality disorder — specifically, borderline personality disorder — resulting in a formal diagnosis being provided.

Diagnosis of personality disorders are undertaken on the basis of specified diagnostic criteria outlined within diagnostic classification manuals of psychological disorders.

Currently, there are two dominant systems: The Diagnostic and Statistical Manual of Mental Disorders (DSM) and the International Classification of Diseases (ICD). In the latest version of the DSM — the DSM-5 — ten distinct personality disorders were outlined and categorized into three clusters, based on shared characteristics (e.g., anxiety, dependency on others, fear of abandonment). Notably, however, the typological approach to personality disorder classification and the underlying structure of personality disorder presented in the DSM is strongly debated. Such debates are primarily a result of most people now coming to understand that individuals generally do not fit into clear categories or types (e.g., Wilmot et al., 2019), as presented in the DSM. In recent years, many have argued for a major change in the entire DSM classification system (e.g., Clark et al., 2017; Newson et al., 2020).

Consequently, in the latest version of the ICD — the ICD-11 — major changes have been outlined regarding personality disorder classification, which are set to come into effect in 2022. The ICD-11 has completely shifted from the traditional typological approach to personality disorder classification (i.e., classification based on the quantity of disorder-related symptoms and behaviors that reach a particular threshold) and instead adopted a dimensional, trait-based approach (i.e., along a continuum of normal-abnormal personality). In this approach, distinct personality disorders are not outlined — meaning that a person would not be classified with a discrete disorder, such as “antisocial personality disorder”. Instead, the focus is on core personality dysfunction and global level of severity, with the ability to classify personality disorders across three levels of severity (i.e., “mild”, “moderate”, "severe”). The diagnostic criteria for personality disorder diagnosis is based on a global 
evaluation of personality functioning, in comparison to arbitrary symptom thresholds. Personality disorder severity assessment is dependent on the overall degree to which personality dysfunction causes disturbances in relation to aspects of the self, interpersonal relationships, affect, cognition, and behavior. An individual with a "severe” personality disorder, for example, might have strong suicidal tendencies and regularly act aggressively towards themselves and others, whereas an individual with a "mild” personality disorder may regularly experience intense mood swings and have a fear of abandonment, but may not act on their negative thoughts.

Discrepancies between the two major psychological disorder diagnostic systems in how personality disorders should be classified exemplifies how little we really know about personality disorder. Moreover, although the ICD approach to personality disorder classification is a move in the right direction, there are still concerns regarding the way in which personality disorders are typically assessed; that is, with a heavy reliance on self-report measures. One important flaw in this regard surrounds the biases that accompany self-report measures, such as social desirability bias and other self-serving biases. Most individuals are motivated to view and present themselves in a positive light, which results in skewed responding to self-reports about problematic and clinically meaningful (but socially undesirable) thoughts, feelings, and behaviors. People may also lack insight into their own thoughts and feelings to allow accurate reporting on a psychological questionnaire or in a clinical interview. Self-report biases are of particular importance in clinical research, as if people are not reporting their symptoms accurately, it could lead to misdiagnosis and inappropriate treatment.

In addition to the issues that typically accompany self-report measures as a result of the questionnaire-takers, there are also issues surrounding the design of self-report measures as a result of the questionnaire-makers. A self-report questionnaire can only capture what we 
ask it to measure. It would be difficult to discern that a person is engaging in self-harm behavior if we only ask them about their exercise regimen, for example. Thus, it is important that we are not only aware of what it is that we want to learn from a given measure, but also that we create and deploy measures that allow participants to tell us information that we might need but may never have thought to ask.

\section{How Can Language Analysis Assist with Personality Disorder Assessment?}

The analysis of natural language has the potential to improve the personality disorder assessment procedure; predominantly resulting from the ability to measure various psychological and personality constructs through language. By looking at people's word use and sentence structure, as illustrated with the examples of the lessons learned from NLP research discussed earlier, we can measure broadly defined emotions, thoughts, and motivations. For example, NLP methods can describe a person's current emotional state (Park \& Conway, 2017), core values (Boyd et al., 2015), and cognitive processes (Khawaja et al., 2014).

There is a vast amount of evidence showing the potential of making precise psychological measurements by analyzing natural language (e.g., Golbeck, 2016; Hall \& Caton, 2017; Yarkoni, 2010). Consequently, it is possible to concurrently measure a wide range of psychological and personality constructs using NLP methods. The ability to measure various psychological and personality constructs all at once allows for a greater understanding of how such constructs are related to one another, and so can provide detailed insight into the structure of one's underlying psychology. Therefore, analysis of the language of people with personality disorder should help to provide insight into the composition and structure of personality disorder. For example, if we find that people with personality disorder who are particularly high in impulsivity always express a substantial amount of emotion in their language, this would provide insight into how two main components of 
personality disorder — impulsivity and affective dysfunction — interact with one another and influence a person's coping behaviors within and across situations.

\section{Understanding the Structure of Personality Disorder}

If language analysis can facilitate a more refined knowledge of the structure of personality disorder, it should be possible to improve the assessment of personality disorder as well. Through language analysis, it is possible to uncover central components of personality disorder. For example, if we find that people with personality disorder consistently use language indicative of disconnection from others, such as relatively few “wewords" and relatively high rates of " $I$-words" and "they-words", this would reveal that a critical feature of the interpersonal dysfunction underlying personality disorder is a fundamental view of oneself as disconnected from others.

Greater understanding of the core components of personality disorder and how they operate would have implications for treatment, as such detailed understanding of core personality disorder components would allow for these components to be a central focus in clinical practice. For example, if the analysis of language provides insight that identity problems arise from an interaction between the formulation of self-concept and aspects of interpersonal dysfunction, this would allow for the development of targeted interventions in clinical practice. Through the computational analysis of the words that people use (and do not use) in close proximity to self-references, then, we may be able to find important, precise aspects of an individual's self-schema that would benefit from further development or restructuring.

Moreover, improved understanding of the underlying structure of personality disorder could feed into the future development of self-report measures in assessing personality disorder, thereby improving the validity of such measures by ensuring that they measure what they are supposed to measure (i.e., core personality disorder features). For example, if the 
analysis of autobiographical narrative text finds that "early romantic frustrations” are a prevalent theme among individuals with personality disorder, this information can be adapted into a more straightforward self-report format, addressing the above-mentioned issues surrounding whether we are "asking the right questions". Additionally, insight into the structure of personality disorders should help to improve the classification procedure by helping to understand whether there are clearly distinct personality disorders with separate underlying processes (i.e., the typological approach), or whether they all have the same underlying processes with slight variations in traits (i.e., the dimensional approach), or potentially some combination of the two.

Definitions of the underlying structure and composition of personality disorder are frequently debated, which is primarily a consequence of highly inconsistent findings across research programs (Wright \& Zimmermann, 2015). For instance, there are still no definitive answers as to what, and how many, core factors comprise personality disorders, or how core factors (e.g., negative affect, interpersonal dysfunction) vary across different types of personality disorder. Stemming from these unanswered questions surrounding the structure of personality disorders, there remains major debates around whether personality disorders are typological or dimensional by nature. And, although many are now moving in favor of the dimensional model, it is not yet known whether the ICD-11 captures this sufficiently. At present, research has attempted to answer questions around the structure of personality disorders by conducting factor analyses to evaluate models of the factors, or processes, underlying personality disorders (Wright, 2017). This typically involves applying factor analytic techniques (i.e., looking at patterns of covariation in measurable behaviors to identify factors) to personality disorder diagnosis criteria (e.g., Wright et al., 2015) and specific personality disorder symptoms and features (e.g., Trull et al., 2012) to determine the underlying factorial structure of personality disorders. However, despite the many valuable 
insights that factor analysis methods have provided regarding the structure of personality disorder, there is still no consensus on how exactly personality disorders are structured.

Accordingly, through the use of NLP methods, there are several ways in which we can improve understanding of the underlying structure and composition of personality disorder. For instance, because words reflect attention (Boyd et al., 2019), it is possible to implicitly see what a person is attending to every time they speak or write. If we can use language to measure many different things that a person is paying attention to, this would allow access to a substantial amount of insightful information about the person, which would take a considerably long time to obtain from a self-report questionnaire and would be sorely lacking in objectivity. In the context of personality disorder, if a person is found (through language analysis) to be paying considerable attention to goal attainment, for example, and negative affect also becomes extremely salient almost always simultaneous to when attending to such goals, this would highlight a critical interaction between the motivational and affective dysfunction components of personality disorder.

The ability to extract a large amount of meaningful information regarding people’s attentional patterns and personality traits from a small amount of language data, such as a social media post, means that language data could be incorporated into factor analyses and complement self-report data in attempting to determine the central factors and processes underlying personality disorder. Complementing self-report data with natural language data will also help to overcome some of the issues associated with self-report measures, as the person will generally not be aware that they are being assessed through their language, reducing the likelihood of biased data.

The potential of language analysis methods to provide insight into the underlying structure and composition of personality disorder can be seen from the examples of the lessons learned from language analysis in general personality research (e.g., Kulkarni et al., 
2018; Pennebaker \& King, 1999; Yarkoni, 2010). The success of language analysis methods in helping to explore and understand the structure of personality demonstrates that it is very possible to do the same with personality disorder, given that the approach would be no different. Additionally, there has in fact been some research that has touched upon the idea of using language analysis to try to understand the structure of personality disorders. Such research has primarily been conducted on what are known to be “dark” personalities, such as psychopathic and narcissistic personalities. For example, language analysis studies have been conducted that have revealed linguistic markers of features, or subfactors, of psychopathy (e.g., callousness; Hancock et al., 2018). Importantly, this demonstrates how personality disorder features can be uniquely and implicitly measured through language and how it is possible to use language to differentiate between specific factors and processes that underlie personality disorders.

It is therefore clear that there is potential to use language analysis methods to gain insight into the underlying structure and composition of personality disorders. Consequently, this would help to improve the accuracy of the assessment and classification of personality disorders, given that it needs to be known what exactly comprises a personality disorder before it can be accurately assessed and classified. Importantly, accurate assessment means accurate diagnosis, which means more appropriate and potentially more effective treatment. Additionally, once it is possible to diagnose someone accurately — not just with what personality disorder they have, but what specific nuances of problems across domains are present (e.g., social, affective, cognitive, etc.) — this would allow intervention to be better targeted, in a more individualized and personalized way.

\section{Improving the Treatment of Personality Disorder}

We have discussed how language analysis can indirectly impact the treatment of personality disorder — through providing insight into the structure of personality disorder 
and improving assessment and classification procedures — but it is also important to discuss how language analysis may directly inform improved personality disorder treatment. Improvements in the treatment of personality disorder is essential as further research is needed to support the efficacy of personality disorder treatments currently available (Bateman et al., 2015). While several studies suggest that psychotherapy is an effective treatment option for borderline personality disorder (Cristea et al., 2017), there is relatively sparse evidence for others, such as antisocial personality disorder (Gibbon et al., 2020). Thus, there in a vital need for improvements in research studying treatments for personality disorder.

Traditionally, treatments for personality disorder (or any clinical condition), whether pharmaceutical or psychotherapeutic, are evaluated through randomized controlled trials (RCTs), otherwise known as clinical trials. Generally speaking, clinical trials involve randomly assigning people to one of two or more conditions, one of which will be a control condition (i.e., not the treatment intervention) and at least one other will be the treatment condition. To evaluate the effectiveness of treatment, baseline outcome measures (e.g., general psychological functioning; symptoms) are assessed before the intervention and again after the intervention, usually with multiple follow-up assessments. These assessments are then compared before and after the intervention and between conditions, allowing for empirical evaluation of the treatment. The RCT approach is seen as the "gold standard" for evaluating the effectiveness of a clinical treatment.

Despite the fact that clinical trials should be the gold standard for evaluating clinical treatments, they are often not conducted according to the standard necessary — that is, in accordance with the guidance on things like appropriate sample size and follow-up length. Regarding personality disorder treatment specifically, one particular issue surrounds the outcome measures used to assess personality disorder treatment, as they are surprisingly 
inconsistent, varied, and often do not measure the same constructs (Bateman et al., 2015), making comparisons between findings difficult. The issue surrounding personality disorder treatment measurement again illustrates our current shortcomings in knowledge around exactly which aspects of personality disorder should improve with treatment and indicates the importance of incorporating new approaches to improve the research evaluating treatments of personality disorder.

With advances in technology (e.g., smartphone sensors), there has been a major uptake in using innovative approaches to monitor psychopathology in the real world (e.g., Ben-Zeev et al., 2015; Seppala et al., 2019; Shatte et al., 2019). Put another way, much attention in clinical research is now being directed towards using technology to observe people's responses to treatment in real-time, outside of therapeutic settings (i.e., in people's natural environments). Accordingly, this is where natural language data fits in. It is possible to monitor the verbal behavior of people with personality disorder throughout the course of treatment, measuring changes in their underlying psychology, emotions, and motivations in response to treatment in real-time. Importantly, this can be done alongside clinical trials, using linguistic features as complementary outcome measures, thereby strengthening the outcome measures currently used in personality disorder research.

The possibility of using natural language data to monitor changes in psychology and mental health over time among people receiving clinical treatment has been well evidenced (e.g., Arevian et al., 2020), and so could be fruitfully applied to clinical personality disorder research. For instance, natural language data could be used to measure psychotherapeutic change in people with personality disorder in response to treatment, which has in fact been explored already (Arntz et al., 2012). Valuably, this exemplifies how linguistic outcome measures could complement other traditional outcome measures of treatment effectiveness 
for personality disorders, providing an implicit measure of current mental state and psychological progress.

As well as utilising natural language measures to investigate outcomes over the course of psychological treatment, a closely linked opportunity for future NLP personality disorder research concerns prediction of treatment outcomes. To illustrate an example of how language analysis could help with the prediction of treatment outcomes, some research has utilized manual transcript scoring methods, such as the Core Conflictual Relationship Theme (CCRT; Luborksy, 1998), to investigate factors related to treatment response (e.g., Hegarty et al., 2020). However, manual scoring of transcripts is very time consuming and effortful. In future, one potential opportunity afforded by NLP methods could be the semi-automation of manual scoring methods, such as the CCRT, through computerization of such methods. Although this approach would require careful consideration to ensure clinical validity, a significant benefit would be the relative ease via which computerized scoring would permit analysis of large-scale data.

Furthermore, the client-therapist relationship represents a particularly salient area to explore given its strong association in predicting psychotherapy outcomes (Flückiger et al., 2018; Wampold et al., 2015). Specifically, language can be used to explore and describe therapeutic alliance through various NLP techniques. One possible technique involves observing similarities in the language style (the way in which words are used and sentences are structured) between the client (e.g., person with personality disorder) and therapist. A language style matching (LSM) score can be quantified to empirically measure this (Gonzales et al., 2010), as can several other NLP techniques, such as conversation-level syntax similarity metric (CASSIM; Boghrati et al., 2018). Importantly, language style similarities are thought to map on to the interpersonal coordination of psychological states (Ireland \& 
Pennebaker, 2010). Thus, measuring the matching of language styles between a client and their therapist should be insightful regarding their psychological connectedness and rapport.

To illustrate the potential to use language to measure client-therapist alliance, one study found that higher LSM between the therapist and client at the start of therapeutic treatment predicted greater therapeutic rapport (Borelli et al., 2019). Additionally, machine learning models built on linguistic features from psychotherapy sessions have been found to have modest accuracy in predicting therapeutic alliance (Goldberg et al., 2020). The ability to implicitly predict the likelihood of a therapeutic alliance forming should help to guide future directions in therapy practice. For example, one could imagine the potential for using language to elucidate client-therapist dyadic interactions at a very early stage in therapy and use this insight to make therapeutic recommendations that will enhance treatment outcomes.

The examples presented illustrate how the analysis of language can be used to guide and improve the treatment of personality disorder. In relation to this, a recent article by Goldberg and colleagues (2020) highlights a number of useful practical suggestions and future recommendations for using machine learning and NLP methods in psychotherapy research, which are informative for future study of personality disorder. Examples of these recommendations include using large datasets, having reasonable expectations, and developing interdisciplinary collaborations across the fields of clinical psychology and computer and data science in particular. The development of such interdisciplinary collaborations should improve the likelihood of the implementation of new technologies into clinical practice, by helping to reduce the barriers between science and practice. Already there are a small number of studies utilizing machine learning in psychotherapy research more broadly (e.g., Aafjes-van Doorn et al., 2020), and so the opportunity for studies in personality disorder populations is a promising area of future research. 


\section{What is the Developmental Trajectory of Personality Disorders?}

In addition to debates around how personality disorders should be assessed, classified, and treated, the developmental trajectory of personality disorders across the lifespan is another area of complexity in personality disorder literature. Put simply, there is much to learn about how personality disorders develop and manifest over time. Specifically, understanding the complexity of gene-environment interactions in both vulnerability and resilience factors is an important area for further research (Amad et al., 2014; Bulbena-Cabre et al., 2018; Marceau et al., 2018; Witt et al., 2017). Questions surrounding how personality disorders manifest over the course of the lifespan have also been debated, primarily due to mixed findings. For instance, in past decades, the main consensus was that personality disorders remain relatively stable over time, whereas recent research suggests that personality disorders have both stable and dynamic aspects (Hopwood \& Bleidorn, 2018). Moreover, there is little knowledge on how personality disorders manifest in later life (Oltmanns \& Balsis, 2011).

Understanding how personality disorders develop and manifest over time is of major importance, as knowing where personality disorders originate from and at what point they are likely to cause serious problems would allow for risk factors to be identified that could inform preventative early interventions. Additionally, knowing how personality disorders are likely to progress throughout life is of value to determine factors, such as particular stages or events in life, that may exacerbate or reduce symptoms. This is useful information regarding the treatment of personality disorders as demographic specific treatment could be provided based on this knowledge, ensuring that treatment is better tailored to the individual. In line with this, if it is known when symptoms are likely to be at their worst, this makes it possible to predict “flare ups”, such as extreme emotional outbursts, which could then be appropriately targeted in a timely manner. 
Research into the origins and developmental trajectory of personality disorders is somewhat limited at present (Bulbena-Cabre et al., 2018; Hopwood \& Bleidorn, 2018), which at least partially explains the lack of clarity on these topics. Another contributing factor to the current lack of consensus on how personality disorders develop stems from the fact that there are considerable variations in how personality disorders manifest over time between individuals, suggesting a need for an individualized, person-centred approach (Hicks et al., 2017). Indeed, an individualized approach is exactly what language analysis methods can provide. Through exploring people's language, there is potential to observe the development and manifestation of personality pathology at an individual level and at a large scale.

\section{How Can Language Analysis Improve Understanding of the Developmental Trajectory of}

\section{Personality Disorders?}

Analysis of natural language can help to provide insight into the development and manifestation of personality disorders given that it is possible to identify markers of psychopathology from language. Research discussed earlier which shown evidence of reliable linguistic markers of psychological disorders, such as depression (e.g., Edwards \& Holtzman, 2017) and schizophrenia (e.g., Coppersmith et al., 2015), illustrates the possibility of using language to detect the presence of psychopathology. Accordingly, linguistic markers of personality pathology could be used, in conjunction with other measures, to help triangulate the onset and course of personality disorders, and thus what has led up to this onset.

To illustrate an example of how such methods may be used to better understand the development of personality disorder, imagine a study which retrospectively measures longitudinal changes in language patterns of individuals diagnosed with personality disorder in the years or even decades leading up to their diagnosis, through easily accessible natural language data, such as social media posts dating back years. If drastic changes in language 
are uncovered, this may point to factors related to the onset of personality disorder symptoms. Valuably, this would help with the identification of important precursors and risk factors for personality disorder development and could complement the increasing focus on prevention and early intervention in the treatment of personality disorder (e.g., Chanen et al., 2017).

Furthermore, the ease of collecting and analyzing large-scale language data makes it possible to take an individualized approach to observing changes in personality pathology over the lifespan, which can be done in real-time. Through precise language measurement, it is possible to observe how underlying psychological and personality processes of personality disorders change over time using a longitudinal, repeated measures design. The ability to measure and track the progress of psychological disorders, such as personality disorder, through language is strongly evidenced by the studies discussed earlier demonstrating the possibility of using language to measure changes in depression (e.g., Park \& Conway, 2017), suicidal ideation (e.g., De Choudhury et al., 2016), and psychotic symptoms (e.g., Birnbaum et al., 2019). This indicates the potential of closely studying language patterns of people with personality disorder across the lifespan, through regular language measurements (e.g., from diaries), to identify markers of personality disorder symptoms and fluctuations in severity. Importantly, the ability to measure manifestations of personality pathology at a large-scale should help to guide treatment on an individual basis and provide an avenue for interventions aimed at prevention and early intervention.

\section{Challenges and Limitations}

In this chapter, we have outlined and provided numerous examples to show how natural language analysis methods can be used to better understand personality disorder. However, despite the many exciting possibilities NLP methods bring to the study of personality disorder, it is important to acknowledge the potential challenges and limitations 
of the application of such methodology in the clinical field. First, it seems necessary to highlight that language analyses conducted on large, naturalistic datasets often result in small to moderate effect sizes (Matz et al., 2017). Likewise, many of the NLP research findings discussed in this chapter consisted of small to moderate effect sizes, which raises questions about the potential impact and practical relevance of such findings.

Nonetheless, the notion that large-scale linguistic analyses often result in small effect sizes can be at least partially be explained by the fact that language data analyzed will typically be naturalistic, meaning that the effects are taking place in the real-world and outside of carefully-designed experimental settings that are largely under meticulous researcher control. The real world is messy and full of confounds, but we can be confident that even when we find a small effect size in such settings, the effect is real and not due to chance. Moreover, as emphasized by Matz and colleagues (2017), modern big-data analyses provide psychologists with new opportunities to identify “weak but reliable signals in a complicated world”. Thus, small effect sizes resulting from big-data analyses can still be highly meaningful and impactful and provide the opportunity to understand the underlying psychology and behavior of billions of people from around the world.

Second, many (perhaps most) language-based studies to date are limited by the fact that they were almost exclusively conducted in the English language. It is therefore unclear how such findings would translate to other languages. For example, it is not yet known whether the findings that people with depression use language indicative of more absolutist, all-or-nothing thinking (Al-Mosaiwi \& Johnstone, 2018) and of a higher cognitive load (Eichstaedt et al., 2018) would be replicated in non-English languages, such as the Russian language. It would be highly valuable for future research to investigate whether associations between language and mental health are universally present or language-specific, as this would have important clinical implications. If such associations are universally present, this 
would mean that there are universal markers of psychopathology that can be incorporated into clinical practice worldwide. However, if the associations found between language and mental health in the English language, such as the association between depression and greater self-focused language, cannot be replicated in other languages, this would contextualise the findings and ensure more accurate interpretation.

Third, we note the importance of ensuring clinical validity of all psychometrics computationally-derived and language-based measures notwithstanding. Given the potential impact that NLP and other big-data computational methods could have on clinical practice, it is critical that these methods allow clinical validity to be maintained. Naturally, the resourceful, easy to access, large-scale nature of NLP methods will greatly appeal to clinical researchers, particularly when compared to more traditional, resource intensive psychological research methods. However, it is important that such modern methods are used ethically and with care by researchers and are informed and guided by clinical expertise and theory. Computational methods will often be best used in combination traditional methods, rather than being used alone, such as the use of linguistic features as complementary outcome measures to assess responses to clinical treatment alongside other traditional outcome measures (e.g., self-reported well-being). Triangulation of research methods in the study of personality disorder will allow for the strengths of such methods to be combined, and thus would generate better and more reliable understanding of personality pathology.

Relatedly, and finally, possibly the most important challenge to using NLP methods to improve understanding and the care and treatment of personality disorder, and psychopathology more generally, surrounds overcoming the barriers between science and clinical practice. This is a particular challenge given the need to consider the clinical validity of computational research methods, as just discussed, and also given that there has traditionally been resistance among clinicians to adopt such methods (Goldberg et al., 2020). 
Thus, greater communication and collaboration between scientists and clinicians is essential for moving forward, in that scientists and clinicians alike would benefit from the sharing of knowledge and advice and developing mutual understanding. The development of such collaborations would undoubtably improve the likelihood of the implementation of new technologies, such as NLP methods, into clinical practice, by helping to reduce the barriers between science and practice.

\section{Conclusions}

Personality disorders are presently some of the most prevalent and high-risk psychological disorders, yet remain poorly understood. Despite extensive study, there is still a lack of clarity on some of the most fundamental aspects of personality disorder, such as the underlying structure and dynamic manifestation over time. Importantly, as evidenced in the wider fields of personality and psychopathology research, natural language processing methods have the potential to improve our understanding of personality disorder. At present, however, there is limited research incorporating language analysis methods in the study personality disorder. Given that personality pathology lies right at the intersection of personality psychology and psychopathology, we believe that the study of personality disorder is abundantly ready for language-based exploration.

In this chapter, we provided illustrative examples of how language analysis can be used to enhance understanding of personality disorder and address some of the fundamental, unanswered questions in the personality disorder literature, including the assessment and classification of personality disorder and developmental trajectory across the lifespan. Such examples demonstrate how language can provide implicit and unobtrusive insight into personality and psychological processes underlying personality pathology at a large-scale, using an individualized approach. 
The growth in sophisticated language analysis methods and powerful statistical techniques allow rich sources of data in the thriving digital world to be analyzed in ways that promote new understanding of psychopathologies, including personality pathology.

Crucially, this research direction represents an opportunity to ensure that both empirical research and clinical practice can reciprocally inform and enhance each other. In order to move forward, interdisciplinary collaborations across clinical and computational research, as well as communication and collaboration between empirical research and clinical practice, are essential. For such promising methods to reach their full potential and have a real-world impact, it is important that they lead to insights that can directly inform clinical interventions and approaches. Taken in all, we hope that this chapter will inspire researchers and clinicians alike to come together and take advantage of the many benefits that the application of natural language processing methods can bring to personality disorder research and practice. 


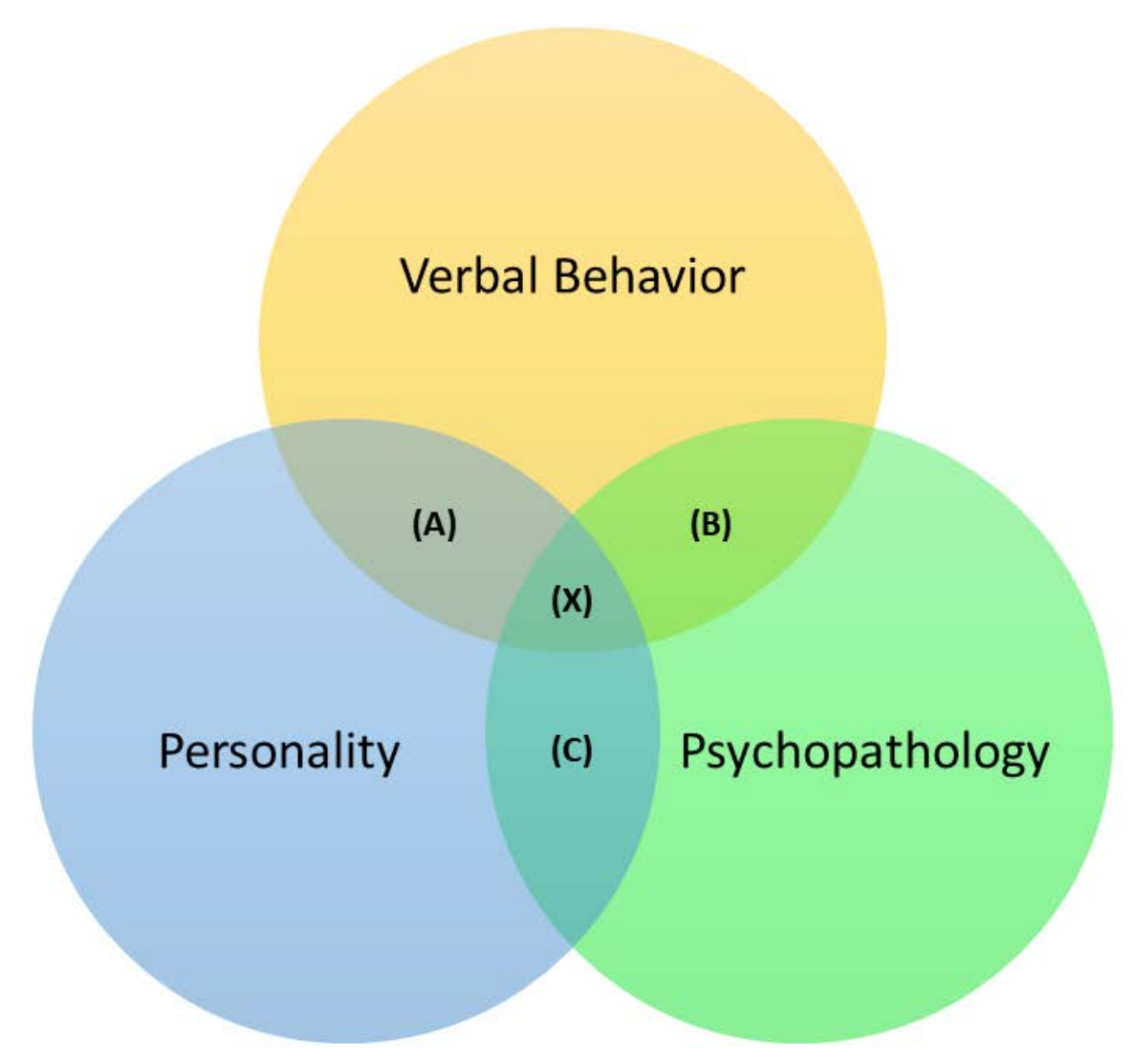

Figure 1. The Intersection of Verbal Behavior, Personality, and Psychopathology. To date, there has been considerable research at the pairwise intersections of Verbal Behavior, Personality, and Psychopathology, but almost no research that integrates all three domains (X). 


\section{References}

Aafjes-van Doorn, K., Kamsteeg, C., Bate, J., \& Aafjes, M. (2020). A scoping review of machine learning in psychotherapy research. Psychotherapy Research. 1-25. https://doi.org/10.1080/10503307.2020.1808729.

Allport, G. W. (1937). Personality: A Psychological Interpretation. New York: Holt.

Al-Mosaiwi, M., \& Johnstone, T. (2018). In an absolute state: Elevated use of absolutist words is a marker specific to anxiety, depression, and suicidal ideation. Clinical Psychological Science, 2167702617747074. https://doi.org/10.1177/2167702617747074

Altamura, A. C., Buoli, M., Caldiroli, A., Caron, L., Cumerlato Melter, C., Dobrea, C., Cigliobianco, M., \& Zanelli Quarantini, F. (2015). Misdiagnosis, duration of untreated illness (DUI) and outcome in bipolar patients with psychotic symptoms: A naturalistic study. Journal of Affective Disorders, 182, 70-75. https://doi.org/10.1016/j.jad.2015.04.024

Amad, A., Ramoz, N., Thomas, P., Jardri, R., \& Gorwood, P. (2014). Genetics of borderline personality disorder: Systematic review and proposal of an integrative model. Neuroscience \& Biobehavioral Reviews, 40, 6-19. https://doi.org/10.1016/j.neubiorev.2014.01.003

American Psychiatric Association. (2013). Diagnostic and Statistical Manual of Mental Disorders (DSM-5®). American Psychiatric Pub.

Arevian, A. C., Bone, D., Malandrakis, N., Martinez, V. R., Wells, K. B., Miklowitz, D. J., \& Narayanan, S. (2020). Clinical state tracking in serious mental illness through computational analysis of speech. PLOS ONE, 15(1), e0225695. https://doi.org/10.1371/journal.pone.0225695

Arntz, A., Hawke, L. D., Bamelis, L., Spinhoven, P., \& Molendijk, M. L. (2012). Changes in natural language use as an indicator of psychotherapeutic change in personality disorders. BehaviourBehavior Research and Therapy, 50(3), 191-202. https://doi.org/10.1016/j.brat.2011.12.007

Bagroy, S., Kumaraguru, P., \& De Choudhury, M. (2017). A social media based index of mental well-being in college campuses. Proceedings of the SIGCHI Conference on Human Factors in Computing Systems, CHI Conference, 1634-1646. https://doi.org/10.1145/3025453.3025909

Barr, K. R., Townsend, M. L., \& Grenyer, B. F. S (2020). Using peer workers with lived experience to support the treatment of borderline personality disorder: A qualitative study of consumer, carer and clinician perspectives. Borderline Personality Disorder and Emotion Dysregulation, 7, 20. https://doi.org/10.1186/s40479-020-00135-5

Bateman, A. W., Gunderson, J., \& Mulder, R. (2015). Treatment of personality disorder. The Lancet, 385(9969), 735-743. doi:10.1016/S0140-6736(14)61394-5

Ben-Zeev, D., Scherer, E. A., Wang, R., Xie, H., \& Campbell, A. T. (2015). Next-generation psychiatric assessment: Using smartphone sensors to monitor behavior and mental health. Psychiatric Rehabilitation Journal, 38(3), 218-226. https://doi.org/10.1037/prj0000130

Birnbaum, M. L., Ernala, S. K., Rizvi, A. F., Arenare, E., R. Van Meter, A., De Choudhury, M., \& Kane, J. M. (2019). Detecting relapse in youth with psychotic disorders utilizing patient-generated and patient-contributed digital data from Facebook. Npj Schizophrenia, 5(1), 17. https://doi.org/10.1038/s41537-019-0085-9 
Boghrati, R., Hoover, J., Johnson, K. M., Garten, J., \& Dehghani, M. (2018). Conversation level syntax similarity metric. Behavior Research Methods, 50, 1055-1073. https://doi.org/10.3758/s13428-017-0926-2

Borelli, J. L., Sohn, L., Wang, B. A., Hong, K., DeCoste, C., \& Suchman, N. E. (2019). Therapist-client language matching: Initial promise as a measure of therapist-client relationship quality. Psychoanalytic Psychology, 36(1), 9-18. https://doi.org/10.1037/pap0000177

Boyd, R. L., Pasca, P., \& Conroy-Beam, D. (2019). You're only Jung once: Building generalized motivational systems theories using contemporary research on language. Psychological Inquiry, 30(2), 93-98. https://doi.org/10.1080/1047840X.2019.1633122

Boyd, R. L., \& Schwartz, H. A. (2021). Natural language analysis and the psychology of verbal behavior: The past, present, and future states of the field. Journal of Language and Social Psychology. https://doi.org/10.1177/0261927X20967028

Boyd, R. L., Wilson, S. R., Pennebaker, J. W., Kosinski, M., Stillwell, D. J., \& Mihalcea, R. (2015). Values in words: Using language to evaluate and understand personal values. Proceedings of the Ninth International AAAI Conference on Web and Social Media, 31-40. http://www.aaai.org/ocs/index.php/ICWSM/ICWSM15/paper/view/10482

Buckholdt, K. E., Parra, G. R., Anestis, M. D., Lavender, J. M., Jobe-Shields, L. E., Tull, M. T., \& Gratz, K. L. (2015). Emotion regulation difficulties and maladaptive behaviors: Examination of deliberate self-harm, disordered eating, and substance misuse in two samples. Cognitive, Therapy, and Research, 39, 140-152.

Bulbena-Cabre, A., Bassir Nia, A., \& Perez-Rodriguez, M. M. (2018). Current knowledge on gene-environment interactions in personality disorders: An update. Current Psychiatry Reports, 20, 74. https://doi.org/10.1007/s11920-018-0934-7 Cahalan, S. (2012). Brain on Fire: My Month of Madness. Free Press: New York.

Carpenter, R. W., \& Trull, T. J. (2013). Components of emotion dysregulation in borderline personality disorder: a review. Current Psychiatry Reports, 15(1), 335. https://doi.org/10.1007/s11920-012-0335-2

Cattell, R. B. (1943). The description of personality: Basic traits resolved into clusters. Journal of Abnormal and Social Psychology, 38(4), 476-506. https://doi.org/10.1037/h0054116

Chanen, A., Sharp, C., Hoffman, P., \& Global Alliance for Prevention and Early Intervention for Borderline Personality Disorder (2017). Prevention and early intervention for borderline personality disorder: A novel public health priority. World Psychiatry: Official Journal of the World Psychiatric Association (WPA), 16(2), 215-216. https://doi.org/10.1002/wps.20429

Charlson, F. J., Ferrari, A. J., Santomauro, D. F., Diminic, S., Stockings, E. Scott, J. G., McGrath, J. J., \& Whiteford, H. A. (2018). Global epidemiology and burden of schizophrenia: findings from the global burden of disease study 2016. Schizophrenia Bulletin, 44(6), 1195-1203. https://doi.org/10.1093/schbul/sby058

Chung, C., \& Pennebaker, J. (2008). Revealing dimensions of thinking in open-ended selfdescriptions: An automated meaning extraction method for natural language. Journal of Research in Personality, 42, 96-132. 10.1016/j.jrp.2007.04.006.

Clark, L. A., Cuthbert, B., Lewis-Fernández, R., Narrow, W. E., Reed, G. M. (2017). Three 
approaches to understanding and classifying mental disorder: ICD-11, DSM-5, and the National Institute of Mental Health's Research Domain Criteria (RDoC).

Psychological Science in the Public Interest, 18(2), 72-145.

doi:10.1177/1529100617727266

Coppersmith, G., Dredze, M., Harman, C., \& Hollingshead, K. (2015). From ADHD to SAD: Analyzing the language of mental health on Twitter through self-reported diagnoses.

Proceedings of the 2nd Workshop on Computational Linguistics and Clinical

Psychology: From Linguistic Signal to Clinical Reality, 1-10.

https://doi.org/10.3115/v1/W15-1201

Cristea, I. A., Gentili, C., Cotet, C. D., Palomba, D., Barbui, C., \& Cuijpers, P. (2017).

Efficacy of psychotherapies for borderline personality disorder: A systematic review and meta-analysis. JAMA Psychiatry, 74(4), 319-328. https://doi.org/10.1001/jamapsychiatry.2016.4287

Dean, H. J., \& Boyd, R. L. (2020). Deep into that darkness peering: A computational analysis of the role of depression in Edgar Allan Poe's life and death. Journal of Affective Disorders, 266, 482-491. https://doi.org/10.1016/j.jad.2020.01.098

De Choudhury, M., Kiciman, E., Dredze, M., Coppersmith, G., \& Kumar, M. (2016). Discovering shifts to suicidal ideation from mental health content in social media. Proceedings of the SIGCHI Conference on Human Factors in Computing Systems, CHI Conference, 2098-2110. https://doi.org/10.1145/2858036.2858207

Digman, J. M. (1990). Personality structure: Emergence of the Five-Factor model. Annual Review of Psychology, 41(1), 417-440. https://doi.org/10.1146/annurev.ps.41.020190.002221

Dunlop, W. L., Karan, A., Wilkinson, D., \& Harake, N. (2020). Love in the first degree: Individual differences in first-person pronoun use and adult romantic attachment styles. Social Psychological and Personality Science, 11(2), 254-265. https://doi.org/10.1177/1948550619847455

Edwards, T., \& Holtzman, N. S. (2017). A meta-analysis of correlations between depression and first person singular pronoun use. Journal of Research in Personality, 68, 63-68. https://doi.org/10.1016/j.jrp.2017.02.005

Eichstaedt, J. C., Smith, R. J., Merchant, R. M., Ungar, L. H., Crutchley, P., Preoţiuc Pietro, D., Asch, D. A., \& Schwartz, H. A. (2018). Facebook language predicts depression in medical records. Proceedings of the National Academy of Sciences, 201802331. https://doi.org/10.1073/pnas.1802331115

Eysenck, H. J. (1991). Dimensions of personality: 16, 5 or 3? Criteria for a taxonomic paradigm. Personality and Individual Differences, 12(8), 773-790. https://doi.org/10.1016/0191-8869(91)90144-Z

Fast, L. A., \& Funder, D. C. (2008). Personality as manifest in word use: Correlations with self-report, acquaintance report, and behavior. Journal of Personality and Social Psychology, 94(2), 334.

Fineberg, S. K., Deutsch-Link, S., Ichinose, M., McGuinness, T., Bessette, A. J., Chung, C. K., \& Corlett, P. R. (2015). Word use in first-person accounts of schizophrenia. The British Journal of Psychiatry, 206(1), 32-38. https://doi.org/10.1192/bjp.bp.113.140046

Flückiger, C., Del Re, A. C., Wampold, B. E., \& Horvath, A. O. (2018). The alliance in adult 
psychotherapy: A meta-analytic synthesis. Psychotherapy, 55, 316-340.

http://dx.doi.org/10.1037/pst0000172

Frankenburg, F. R., \& Zanarini, M. C. (2004). The association between borderline personality disorder and chronic medical illnesses, poor health-related lifestyle choices, and costly forms of health care utilization. The Journal of Clinical Psychiatry, 65(12), 1660-1665. https://doi.org/10.4088/JCP.v65n1211

Freud, S. (1891). On Aphasia: A Critical Study [Zur Auffassung der Aphasien: eine kritische Studie]. Stengel, E., translator. New York: International UP.

Freud, S. (1915). The Unconscious. SE, 14: 159-215.

Gabbard, G. (2012). Treatment Resistance in Personality Disorders. In Management of Treatment-Resistant Major Psychiatric Disorders. Oxford, UK: Oxford University Press. Retrieved from https://oxfordmedicine.com/view/10.1093/med/9780199739981.001.1/med9780199739981-chapter-0013.

Gibbon, S., Khalifa, N. R, Cheung, N.H.-Y., Völlm, B. A., \& McCarthy, L. (2020). Psychological interventions for antisocial personality disorder. Cochrane Database of Systematic Reviews, 9, CD007668. https://doi.org/10.1002/14651858.CD007668.pub3.

Gilbert, F., Daffern, M., Talevski, D., \& Ogloff, J. (2013). Understanding the personality disorder and aggression relationship: an investigation using contemporary aggression theory. Journal of Personality Disorders, 29(1), 100-114. https://doi.org/10.1521/pedi_2013_27_077

Golbeck, J. A. (2016). Predicting personality with social media. AIS Transactions on Replication Research, 2(2), 1-10.

Goldberg, S. B., Flemotomos, N., Martinez, V. R., Tanana, M. J., Kuo, P. B., Pace, B. T., Villatte, J. L., Georgiou, P. G., Van Epps, J., Imel, Z. E., Narayanan, S. S., \& Atkins, D. C. (2020). Machine learning and natural language processing in psychotherapy research: Alliance as example use case. Journal of Counseling Psychology, 67(4), 438-448. https://doi.org/10.1037/cou0000382

Gonzales, A., Hancock, J., \& Pennebaker, J. (2010). Language style matching as a predictor of social dynamics in small groups. Communication Research, 37, 3-19. Doi: $10.1177 / 0093650209351468$.

Gottschalk, L. A. (2000). The application of computerized content analysis of natural language in psychotherapy research now and in the future. American Journal of Psychotherapy, 54(3), 305-311.

Guntuku, S. C., Sherman, G., Stokes, D. C., Agarwal, A. K., Seltzer, E., Merchant, R. M., \& Ungar, L. H. (2020). Tracking mental health and symptom mentions on Twitter during COVID-19. Journal of General Internal Medicine, 35(9), 2798-2800. https://doi.org/10.1007/s11606-020-05988-8

Hall, M., \& Caton, S. (2017). Am I who I say I am? Unobtrusive self-representation and personality recognition on Facebook. PLOS ONE, 12(9), e0184417. https://doi.org/10.1371/journal.pone.0184417

Hancock, J. T., Woodworth, M., \& Boochever, R. (2018). Psychopaths online: The linguistic traces of psychopathy in email, text messaging and Facebook. Media and Communication, 6(3), 83-92. https://doi.org/10.17645/mac.v6i3.1499

Hegarty, B. D., Marceau, E. M., Gusset, M., \& Grenyer, B. F. S. (2019). Early treatment 
response in psychotherapy for depression and personality disorder: Links with core conflictual relationship themes. Psychotherapy Research, 30(1), 112-123. https://doi.org/https://doi.org/10.1080/10503307.2019.1609114

Hicks, B. M., Clark, D. A., \& Durbin, C. E. (2017). Person-centered approaches in the study of personality disorders. Personality Disorders, 8(4), 288-297. https://doi.org/10.1037/per0000212

Hopwood, C. J., \& Bleidorn, W. (2018). Stability and change in personality and personality disorders. Current Opinion in Psychology, 21, 6-10. https://doi.org/10.1016/j.copsyc.2017.08.034

Horvath, A. O., \& Symonds, B. D. (1991). Relation between working alliance and outcome in psychotherapy: A meta-analysis. Journal of Counseling Psychology, 38(2), 139-149. https://doi.org/10.1037/0022-0167.38.2.139

Ireland, M. E., \& Pennebaker, J. W. (2010). Language style match-ing in writing: Synchrony in essays, correspondence, and poetry. Journal of Personality and Social Psychology, 99, 549-571.

John, O. P., Angleitner, A., \& Ostendorf, F. (1988). The lexical approach to personality: A historical review of trait taxonomic research. European Journal of Personality, 2(3), 171-203. https://doi.org/10.1002/per.2410020302

Kahn, J., Tobin, R., Massey, A., \& Anderson, J. (2007). Measuring emotional expression with the Linguistic Inquiry and Word Count. The American Journal of Psychology, 120, 263-286. 10.2307/20445398.

Khawaja, M. A., Chen, F., \& Marcus, N. (2014). Measuring cognitive load using linguistic features: Implications for usability evaluation and adaptive interaction design. International Journal of Human-Computer Interaction, 30(5), 343-368. https://doi.org/10.1080/10447318.2013.860579

Kim, Y. R., \& Tyrer, P. (2010). Controversies surrounding classification of personality disorder. Psychiatry Investigation, 7(1), 1-8. https://doi.org/10.4306/pi.2010.7.1.1

Kramer, A. D., \& Chung, C. K. (2011). Dimensions of self-expression in Facebook status updates. ICWSM.

Kulkarni, V., Kern, M. L., Stillwell, D., Kosinski, M., Matz, S., Ungar, L., Skiena, S., \& Schwartz, H. A. (2018). Latent human traits in the language of social media: An openvocabulary approach. PLOS ONE, 13(11), e0201703.

https://doi.org/10.1371/journal.pone.0201703

Luborsky, L., \& Crits-Christoph, P. (1998). Understanding Transference: The Core Conflictual Relationship Theme Method (2nd ed.). American Psychological Association.

Lyons, M., Aksayli, N. D., \& Brewer, G. (2018). Mental distress and language use: Linguistic analysis of discussion forum posts. Computers in Human Behavior, 87, 207-211. https://doi.org/10.1016/j.chb.2018.05.035

Mairesse, F., Walker, M. A., Mehl, M. R., \& Moore, R. K. (2007). Using linguistic cues for the automatic recognition of personality in conversation and text. Journal of Artificial Intelligence Research, 30, 457-500. https://doi.org/10.1613/jair.2349

Ma-Kellams, C., Or, F., Baek, J. H., \& Kawachi, I. (2016). Rethinking suicide surveillance: Google Search data and self-reported suicidality differentially estimate completed suicide risk. Clinical Psychological Science, 4(3), 480-484. https://doi.org/10.1177/2167702615593475

Marceau, E. M., Meuldijk, D., Townsend, M. L., Solowij, N., \& Grenyer, B. F. S. (2018). 
Biomarker correlates of psychotherapy outcomes in borderline personality disorder: A systematic review. Neuroscience \& Biobehavioral Reviews, 94, 166-178. https://doi.org/10.1016/j.neubiorev.2018.09.001

Martindale, C. (1975a). The grammar of altered states of consciousness: A semiotic reinterpretation of aspects of psychoanalytic theory. Psychoanalysis and Contemporary Science, 4, 331-354.

Matz, S. C., Gladstone, J. J., \& Stillwell, D. (2017). In a world of big data, small effects can still matter: A reply to Boyce, Daly, Hounkpatin, and Wood (2017). Psychological Science, 28(4), 547-550. https://doi.org/10.1177/0956797617697445

McMurran, M., Huband, N., \& Overton, E. (2010). Non-completion of personality disorder treatments: A systematic review of correlates, consequences, and interventions. Clinical Psychology Review, 30(3), 277-287. https://doi.org.ezproxy.uow.edu.au/10.1016/j.cpr.2009.12.002

Mergenthaler E., \& Kächele H. (1988). The Ulm Textbank Management System: A tool for psychotherapy research. In Dahl H., Kächele H., \& Thomä H. (eds.), Psychoanalytic Process Research Strategies. Springer: Berlin, Heidelberg. https://doi.org/10.1007/978-3-642-74265

Newson, J. J., Hunter, D., \& Thiagarajan, T. C. (2020). The heterogeneity of mental health assessment. Frontiers in Psychiatry, 11, 76. https://doi.org/10.3389/fpsyt.2020.00076

Oltmanns, T. F., \& Balsis, S. (2011). Personality disorders in later life: Questions about the measurement, course, and impact of disorders. Annual Review of Clinical Psychology, 7, 321-349. https://doi.org/10.1146/annurev-clinpsy-090310-120435

Onraet, E., Hiel, A. V., \& Dhont, K. (2013). The relationship between right-wing ideological attitudes and psychological well-being. Personality and Social Psychology Bulletin. 39(4), 509-522. https://doi.org/10.1177/0146167213478199

Park, A., \& Conway, M. (2017). Longitudinal changes in psychological states in online health community members: Understanding the long-term effects of participating in an online depression community. Journal of Medical Internet Research, 19(3), e71. https://doi.org/10.2196/jmir.6826

Pennebaker, J. W., Boyd, R. L., Jordan, K., \& Blackburn, K. (2015). The Development and Psychometric Properties of LIWC2015. Retrieved from https://repositories.lib.utexás.edu/bitstream/handle/2152/31333/LIWC2015_Language Manual.pdf

Pennebaker, J. W., \& King, L. A. (1999). Linguistic styles: Language use as an individual difference. Journal of Personality and Social Psychology, 77(6), 1296-1312. https://doi.org/10.1037/0022-3514.77.6.1296

Pennebaker, J. W., Mehl, M. R., \& Niederhoffer, K. G. (2003). Psychological aspects of natural language use: Our words, our selves. Annual Review of Psychology, 54, 547577.

Schneider, B., Schnabel, A., Wetterling, T., Bartusch, B., Weber, B., \& Georgi, K. (2008). How do personality disorders modify suicide risk? Journal of Personality Disorders, 22(3), 233-245. https://doi.org/10.1521/pedi.2008.22.3.233

Schwartz, H. A., Eichstaedt, J., Kern, M. L., Park, G., Sap, M., Stillwell, D., Kosinski, M., \& Ungar, L. (2014). Towards assessing changes in degree of depression through Facebook. Proceedings of the Workshop on Computational Linguistics and Clinical 
Psychology: From Linguistic Signal to Clinical Reality, 118-125. https://www.aclweb.org/anthology/W14-3214

Seppala, J., Vita, I., Jamsa, T., Miettunen, J., Isohanni, M., Rubinstein, K., Feldman, Y., Grasa, E., Corripio, I., Berdun, J., D'Amico, E., \& Bulgheroni, M. (2019).

Smartphone and wearable sensors-based m-Health approach for psychiatric disorders and symptoms - a systematic review and link to m-RESIST project (Preprint). JMIR Mental Health, 6(2), e9819. https://doi.org/10.2196/mental.9819

Shatte, A. B. R., Hutchinson, D. M., \& Teague, S. J. (2019). Machine learning in mental health: a scoping review of methods and applications. Psychological Medicine, 49(9), 1-23. https://doi.org/10.1017/S0033291719000151

Sonnenschein, A. R., Hofmann, S. G., Ziegelmayer, T., \& Lutz, W. (2018). Linguistic analysis of patients with mood and anxiety disorders during cognitive behavioral therapy. Cognitive Behaviour Therapy, 47(4), 315-327. https://doi.org/10.1080/16506073.2017.1419505

Steel, Z., Marnane, C., Iranpour, C., Chey, T., Jackson, J. W., Patel, V., \& Silove, D. (2014). The global prevalence of common mental disorders: a systematic review and metaanalysis 1980-2013. International Journal of Epidemiology, 43(2), 476-493. https://doi.org/10.1093/ije/dyu038

Stelmack, R. M., \& Stalikas, A. (1991). Galen and the humour theory of temperament. Personality and Individual Differences, 12(3), 255-263. https://doi.org/10.1016/01918869(91)90111-N

Tackman, A. M., Baranski, E. N., Danvers, A. F., Sbarra, D. A., Raison, C. L., Moseley, S. A., Polsinelli, A. J., \& Mehl, M. R. (in press). 'Personality in its Natural Habitat' revisited: A pooled, multi-sample examination of the relationships between the Big Five personality traits and daily behaviour and language use. European Journal of Personality. https://doi.org/10.1002/per.2283

Trull, T. J., Vergés, A., Wood, P. K., Jahng, S., \& Sher, K. J. (2012). The structure of Diagnostic and Statistical Manual of Mental Disorders (4th edition, text revision) personality disorder symptoms in a large national sample. Journal of Personality Disorders, 3(4), 355-369.

Tyrer, P., Reed, G. M., \& Crawford, M. J. (2015). Classification, assessment, prevalence, and effect of personality disorder. The Lancet, 385(9969), 717-726. https://doi.org/10.1016/S0140-6736(14)61995-4

Wampold, B. E. (2015). How important are the common factors in psychotherapy? An update. World Psychiatry, 14(3), 270-277. https://doi.org/10.1002/wps.20238

Wilmot, M. P., Haslam, N., Tian, J., \& Ones, D. S. (2019). Direct and conceptual replications of the taxometric analysis of Type A behavior. Journal of Personality and Social Psychology, 116(3), 12-26. https://doi.org/10.1037/pspp0000195

Winsper, C. (2018). The aetiology of borderline personality disorder (BPD): Contemporary theories and putative mechanisms. Current Opinion in Psychology, 21, 105-110. https://doi.org/10.1016/j.copsyc.2017.10.005.

Winsper, C., Bilgin, A., Thompson, A., Marwaha, S., Chanen, A. M., Singh, S. P., Wang, A., \& Furtado, V. (2020). The prevalence of personality disorders in the community: a global systematic review and meta-analysis. British Journal of Psychiatry, 216(2), 69-78. https://doi.org/10.1192/bjp.2019.166

Witt, S. H., Streit, F., Jungkunz, M., Frank, J., Awasthi, S., Reinbold, C. S., Treutlein, J., 
Degenhardt, F., Forstner, A. J., Heilmann-Heimbach, S., Dietl, L., Schwarze, C. E., Schendel, D., Strohmaier, J., Abdellaoui, A., Adolfsson, R., Air, T. M., Akil, H., Alda, M., Alliey-Rodriguez, N., ... Rietschel, M. (2017). Genome-wide association study of borderline personality disorder reveals genetic overlap with bipolar disorder, major depression and schizophrenia. Translational Psychiatry, 7(6), e1155. https://doi.org/10.1038/tp.2017.115

Wojcik, S. P., Hovasapian, A., Graham, J., Motyl, M., \& Ditto, P. H. (2015). Conservatives report, but liberals display, greater happiness. Science, 347(6227), 1243-1246. https://doi.org/10.1126/science.1260817

Wright, A. G. C. (2017). The current state and future of factor analysis in personality disorder research. Personality Disorders: Theory, Research, and Treatment, 8(1), 14-25. https://doi.org/10.1037/per0000216

Wright, A. G. C., Scott, L. N., Stepp, S. D., Hallquist, M. N., \& Pilkonis, P. A. (2015). Personality pathology and interpersonal problem stability. Journal of Personality Disorders, 29(5), 684-706.

Wright, A. G. C., \& Simms, L. J. (2016). Stability and fluctuation of personality disorder features in daily life. Journal of Abnormal Psychology, 125(5), 641-656. https://doi.org/10.1037/abn0000169

Wright, A. G. C, \& Zimmerman, J. (2015). At the nexus of science and practice: Answering basic clinical questions in personality disorder assessment and diagnosis with quantitative modeling techniques. In Huprich, S., (Eds.), Personality Disorders: Toward Theoretical and Empirical Integration in Diagnosis and Assessment, pp. 109144. American Psychological Association: Washington, DC.

Yarkoni, T. (2010). Personality in 100,000 words: A large-scale analysis of personality and word use among bloggers. Journal of Research in Personality, 44(3), 363-373. https://dx.doi.org/10.1016\%2Fj.jrp.2010.04.001

Zimmermann, J., Brockmeyer, T., Hunn, M., Schauenburg, H., \& Wolf, M. (2017). Firstperson pronoun use in spoken language as a predictor of future depressive symptoms: Preliminary evidence from a clinical sample of depressed patients. Clinical Psychology \& Psychotherapy, 24(2), 384-391. https://doi.org/10.1002/cpp.2006

Zomick, J., Levitan, S. I., \& Serper, M. (2019). Linguistic analysis of schizophrenia in Reddit posts. Proceedings of the Sixth Workshop on Computational Linguistics and Clinical Psychology, 74-83. 